\title{
Influence of High Current Load on Electrical Properties of Adhesive Conductive Joints
}

\author{
Aleš Duraj, Pavel Mach, Radoslav Radev, Jan Matějec \\ Czech Technical University, Department of Electrotechnology \\ Prague 6, 166 27, Czech Republic \\ E-mail: duraja@centrum.cz
}

\begin{abstract}
Isotropic and anisotropic electrically conductive adhesives (ICAs and ACAs) are alternative materials for substitution of common used tin-lead solders in electronic assembly. Electrically conductive adhesives are potential materials for the bonding of surface mounted components and for some special applications. In this research we are focused on an investigation of influence of high current load on changes of quality of adhesive joints. Monitored parameters are electrical resistance and nonlinearity of $V-C$ characteristics. Research is divided into two types of high current load: a) direct current (DC), amplitude $1 \mathrm{~A}$, b) current pulses 1:1, $f=500 \mathrm{~Hz}$, amplitude $1.41 \mathrm{~A}$.
\end{abstract}

\section{Introduction}

Isotropic and anisotropic electrically conductive adhesives (ICAs and ACAs) are alternative materials for substitution of common used tin-lead solders in electronic assembly. Electrically conductive adhesives (ECAs) were developed especially for joining in applications where the use of high temperature (necessary for soldering) is impossible. Basic material of ICAs is usually epoxy or acrylic resin (insulating material) and electrically conductive filler (Ag flakes or balls). Electrically conductive adhesives, especially ACAs and ACFs are potential materials for the bonding of surface mounted components and for some special applications, e.g. flip-chip assembly, chip-on-film (COF), chip-on-glass (COG) or for flexible circuit assembly applications (chip-on-flex). ACFs are also extensively used for connection between PCBs and LCD or liquid crystal module (LCM). Joining with anisotropic conductive adhesives and films is very fast and successfully spreading technology because of there is no requirement for applying additional underfill [1]. The basic materials of ACAs are thermoset or thermoplastic (usually epoxy resin) with conductive filler - mainly balls with conductive layer (polymer $+\mathrm{Au}, \mathrm{Ni}+\mathrm{Au}$ ). These particles can be deformed between bonding electrodes during actual bonding and this deformation increases the contact area between the conducting particles and bonding electrodes. Thus it lowers the interconnection resistance [2]. The main advantages of these types of conductive adhesives are anisotropic conductivity and suitability for fine-pitch connections where the space between leads is very small $(<125 \mu \mathrm{m})$. The disadvantage of ACAs and $\mathrm{ACFs}$ is a requirement of pressure during whole curing process. Pressure and heat (thermocompression) are applied simultaneously so that the conductive particles can make contact with both bumps and substrate tracks and to be electrically connected.

Quality of these adhesive joints is evaluated according to their electrical and mechanical properties. In this research we are focused on an investigation of influence of high current load (direct current and pulse current) on changes of quality of adhesive joints. Also investigation of influence of bonding pressure of tested ACA has been carried out. Curing pressure has been chosen in a range $3 \mathrm{MPa}$ to $10 \mathrm{MPa}$ and evaluated its effect on quality of adhesive joint. Monitored parameters are electrical resistance and nonlinearity of $\mathrm{V}-\mathrm{C}$ characteristics.

\section{Experiments}

Investigation of influence of high current load on basic electrical properties of adhesive joints is significant especially for high power components because of electrical current and high temperature has radical effect on quality and reliability of bonds. Experiment has been divided into two parts - study of effects of high direct current (DC) which is passing through testing adhesive joints and also testing of influence of high current pulses. Parameters of loading conditions:

a) $\mathrm{DC}: \mathrm{I}_{\mathrm{m}}=\mathrm{I}_{\mathrm{rms}}=1 \mathrm{~A} / 50$ hours

b) Current pulses : $I_{m}=1,41 \mathrm{~A}\left(\mathrm{I}_{\mathrm{rms}}=1 \mathrm{~A}\right) / 50$ hours, $1: 1\left(\mathrm{t}_{1}=1 \mathrm{~ms}, \mathrm{~T}=2 \mathrm{~ms}\right), \mathrm{f}=500 \mathrm{~Hz}$

Both types of high current load were carried out for a 50 hours in ambient conditions $\left(20^{\circ} \mathrm{C} / 30 \%\right.$ RH) without special cooling of testing boards.

DC has been provided with power supply with stabilized output current. Generator of pulse current has been developed on department of 
electrotechnology. Power supply for this generator has been the same as for DC load.

Effective values $\left(\mathrm{I}_{\mathrm{rms}}\right)$ of loading currents have been chosen the same $(1 \mathrm{~A})$ for both types of loads because of identical thermal effects (depending on resistance tested bonds). For DC load is $\mathrm{I}_{\mathrm{m}}=\mathrm{I}_{\mathrm{rms}}=1$ $\mathrm{A}$ and for current pulses is maximum loading current $\mathrm{I}_{\mathrm{m}}=1,41 \mathrm{~A}$ - according to equations (1) and (2).

$$
\begin{aligned}
& I_{\text {rms }}=\sqrt{\frac{1}{T} \cdot \int_{0}^{T / 2} I_{M}{ }^{2} d t}=\frac{I_{M}}{\sqrt{2}} \\
& I_{\text {rms }}=\frac{I_{M}}{\sqrt{2}}=\frac{1,41}{\sqrt{2}}=1 \mathrm{~A}
\end{aligned}
$$

Experiment has been divided into investigation of isotropic and also anisotropic electrically conductive adhesives. Tab.1. shows selected ECAs (3 types of ICAs and 1 type of ACA) for measurements.

Table 1. Tested Electrically Conductive Adhesives.

\begin{tabular}{|l|l|}
\hline \multicolumn{1}{|c|}{ Type } & \multicolumn{1}{|c|}{ Properties } \\
\hline \hline $\begin{array}{l}\text { Amepox AX 20 } \\
\text { ICA (one-component } \\
\text { adhesive) }\end{array}$ & $\begin{array}{l}\text { bisphenol epoxy } \\
\text { resin } \\
+ \text { formulated } \mathrm{BF}_{3} \\
75 \% \mathrm{Ag} \text { flakes }\end{array}$ \\
\hline $\begin{array}{l}\text { Amepox ER 55 } \\
\text { ICA (one-component } \\
\text { adhesive) }\end{array}$ & $\begin{array}{l}\text { bisphenol epoxy } \\
\text { resin } \\
+ \text { butyl glycidyl ether } \\
75 \% \mathrm{Ag} \text { flakes }\end{array}$ \\
\hline $\begin{array}{l}\text { Amepox ER 656S } \\
\text { ICA (two-component } \\
\text { adhesive) }\end{array}$ & $\begin{array}{l}\text { bisphenol epoxy } \\
\text { resin } \\
+ \text { formulated } \\
\text { polyamine } \\
80 \% \text { Ag flakes }\end{array}$ \\
\hline LOCTITE 3447 & $\begin{array}{l}\text { Epoxy resin } \\
\text { ACA filler (Au coated) } \\
\text { ACA }\end{array}$ \\
\hline
\end{tabular}

Quality of these adhesives joints is evaluated according to their electrical parameters:

1) Electrical resistance $R_{s}$ of the single adhesive joint

2) Nonlinearity of $\mathrm{C}-\mathrm{V}$ characteristics of 2 joints + SMD

\section{Preparation of testing samples}

Basic material of testing board (PCB) is common used fibreglass laminate FR4 - shown in Figure 1. Material of conductive paths is plated $35 \mu \mathrm{m} \mathrm{Cu}$ foil.
Three types of surface metallization of conductive paths have been used:

1) $\mathrm{Cu}$

2) $\mathrm{Cu}+\sim 50 \mu \mathrm{m}$ Sn (HASL)

3) $\mathrm{Cu}+5 \mu \mathrm{m} \mathrm{Ni}+1 \mu \mathrm{m} \mathrm{Au}$

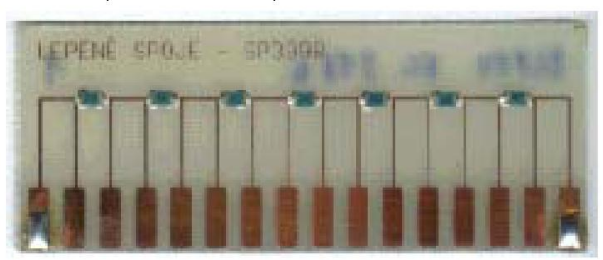

Figure 1. Assembled testing board

Tested joints have been prepared with assembly of SMD resistors (type 1206 0R0, Microtech $\mathrm{GmbH}$ ) with special contacts metallization $(\mathrm{CrNi}-\mathrm{Cu}-\mathrm{Ag}$ ) for adhesive connections - depicted in Figure 2.

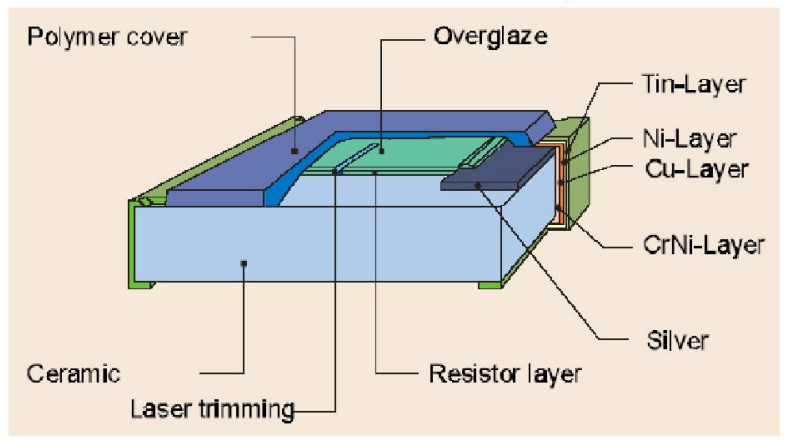

Figure 2. SMD resistor with lead-free contacts.

Adhesives have been deposited on the PCB in defined amount by injection method, assembled with SMD resistors and then have been cured under defined conditions (approx. 120-150 ${ }^{\circ} \mathrm{C} / 10-30$ $\min$.)

All analyses of the ACA have been carried out in a range of bonding pressure 3 to $10 \mathrm{MPa}(6-20 \mathrm{~N} /$ SMD) for investigation of influence of curing pressure on quality of joints. ACA was cured with hot air under defined temperature and various pressure conditions.

Effective value $\mathrm{I}_{\mathrm{rms}}$ of loading current $(1 \mathrm{~A})$ has been selected according to max. power load of SMD resistors. Typical electrical resistance of single adhesive joint is around 20-30 $\mathrm{m} \Omega$ and used SMD resistors have resistance around $10 \mathrm{~m} \Omega$. According to equation (3) the power dissipation in one assembled SMD resistor is about 0,05-0,07 W which is $1 / 4$ of max power $P_{\max }$ of SMD resistor $(0,25 \mathrm{~W})$.

$$
P=U \cdot I=R \cdot I^{2}
$$

At these power conditions the SMDs and joints temperature is up to $40{ }^{\circ} \mathrm{C}\left(\Delta \mathrm{T} \sim 20^{\circ} \mathrm{C}\right)$. These 
experiments are mainly focused only on an effect of high current on changes of joint resistance and nonlinearity of $\mathrm{C}-\mathrm{V}$ characteristics. So this temperature is a compromise between the highest current load and temperatures which have only very slight effects on measured parameters of adhesive bonds. Applied current could be higher but influence of the temperature should be indispensable. Measurement of temperatures has been accomplished with accurate thermo-vision method. For some testing samples the joint resistance increase rapidly and power dissipation overpass tolerable value of $\mathrm{P}_{\max }$ of SMD. These resistors have burned up and therefore these SMDs have been rejected from evaluations. Example of measurement of temperature conditions on testing boards during high current load is shown in Figure 3.

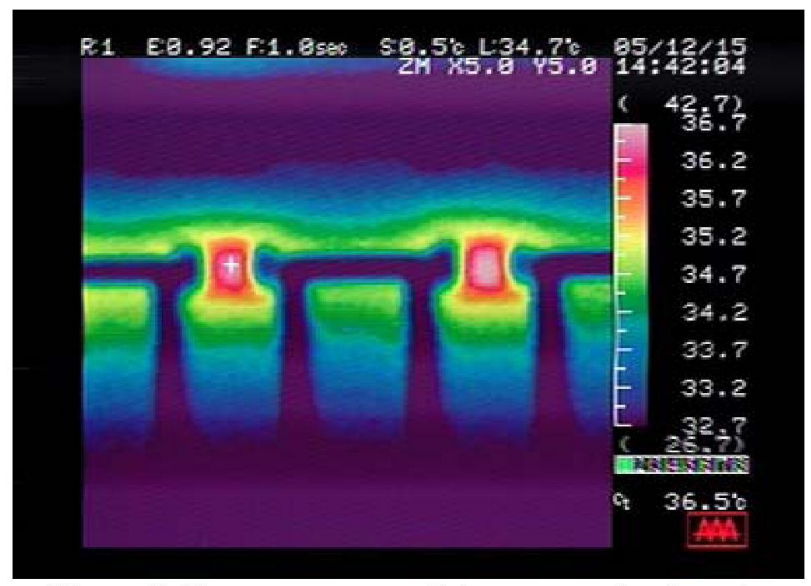

Figure 3. Temperature conditions on testing board.

\section{Electrical resistance of the joints}

Resistance of the joints has been measured with the LCR meter HP 4248. The samples have been contacted with four-point probe method. The resistance of single resistors has been measured $\left(R_{r}=\right.$ $10 \mathrm{~m} \Omega$ ). Then the system SMD resistor +2 joints assembled on the board has been measured $\left(R_{M}\right)$ Single joint resistance $R_{S}$ is evaluated according to equation (4).

$$
R_{s}=\frac{R_{M}-R r}{2}
$$

\section{Tested Isotropic Conductive Adhesives:}

Table 2. Measured initial joint resistance Rs of ICA

\begin{tabular}{|c|c|c|c|}
\hline \multicolumn{4}{|c|}{ Initial joint resistance Rs [m $]$} \\
\hline & Cu pads & $\begin{array}{c}\text { Ni/Au } \\
\text { pads }\end{array}$ & Sn pads \\
\hline \hline AX 20 & 24,1 & 25,0 & 13000,0 \\
\hline ER 55MN & 17,6 & 15,6 & 51,4 \\
\hline ER 656 S & 32,0 & 32,9 & 89,0 \\
\hline
\end{tabular}

Table 3. Change of joint resistance $\mathrm{R}_{s}$ of ICAs after 50 hours of high DC and current pulses load.

\begin{tabular}{|c|c|c|c|}
\hline \multicolumn{4}{|c|}{ Change of joint resistance [\%] - DC load (50 } \\
hours)
\end{tabular}
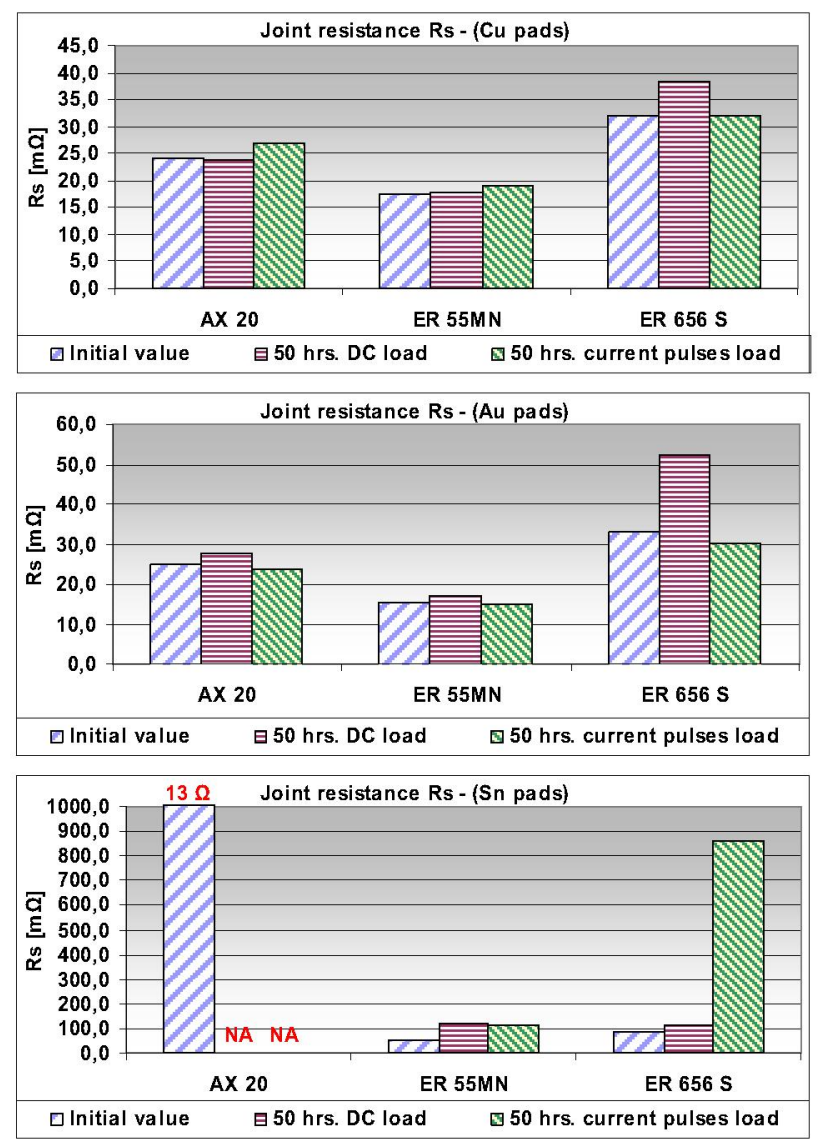

Figure 4. Influence of high current loads and types of pads metallization on joint resistance $R_{s}$ of ICAs.

Initial joint resistance Rs of tested ICAs is in the range 20-100 $\mathrm{m} \Omega$ and depends on the type of pads metallization. From this measurements and also from other experiments [3] is clear that most of ICAs is not very suitable for connection on pure $\mathrm{Sn}$ metallization. Differences between other types of surface finishes are not too high. Changes of Rs are not too different $(< \pm 20 \%)$ for both DC and current pulses load $(50 \mathrm{hrs}$.). Only for Sn pads is shift much 
higher (increase of Rs up to 8-times). Unexpected result is that on $\mathrm{Ni} / \mathrm{Au}$ pads metallization the joint resistance has increased after DC load but after current pulses load Rs decreases for all three types of ICAs. For better understanding of this fact is probably necessary to accomplish rather longer high current loadings.

\section{Tested Anisotropic Conductive Adhesive:}

Table 4. Measured initial joint resistance $R_{s}$ of ACA

\begin{tabular}{|c|c|c|c|}
\hline \multicolumn{4}{|c|}{ Initial joint resistance Rsavg [m [} \\
\hline & Cu pads & Au pads & Sn pads \\
\hline 2,99 & 25,6 & 24,6 & 20,2 \\
\hline 3,54 & 25,1 & 26,3 & 22,2 \\
\hline 4,43 & 23,1 & 24,7 & 20,7 \\
\hline 5 & 22,1 & 21,9 & 19,5 \\
\hline 10 & 20,5 & 23,2 & 19,4 \\
\hline
\end{tabular}

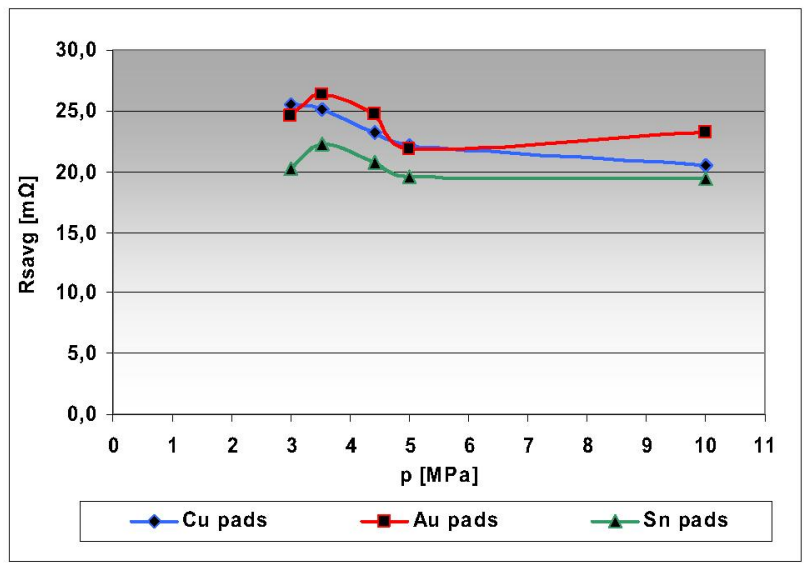

Figure 5. Effect of bonding pressure and pads metallization on the joint resistance of ACA.

Influence of bonding pressure on joint resistance is shown in Figure 5. From this measurements and also from other experiments [4] is clear that joint resistance $R_{s}$ decreases with rising bonding pressure. Differences between tested $\mathrm{Cu}, \mathrm{Ni} / \mathrm{Au}$ and $\mathrm{Sn}$ metallization are not very strong. For bonding pressure $p>5 \mathrm{MPa}$ is joint resistance $R_{\mathrm{S}}$ approx. between 20 and $25 \mathrm{~m} \Omega$ and it is stabilized. Effect of $\mathrm{DC}$ or current pulses load on $\mathrm{R}_{\mathrm{s}}$ has not linear tendency depending on bonding pressure. It is probably caused by random generation and distribution of defects in interconnections between component leads, conductive particle in ACA and pad of PCB. These interconnections could be probably also improved by high current which is passing through. Local heating, caused by high current density, in boundaries between conductive particles and substrate pads (component leads) could create better electrical connection and joint resistance decreases. Nevertheless bonding pressure $p>5 \mathrm{MPa}$ has decreasing effect on change of $\mathrm{R}_{s}$. Shifts of $\mathrm{R}_{\mathrm{s}}$ above this bonding pressure are less than $\pm 5 \%$.
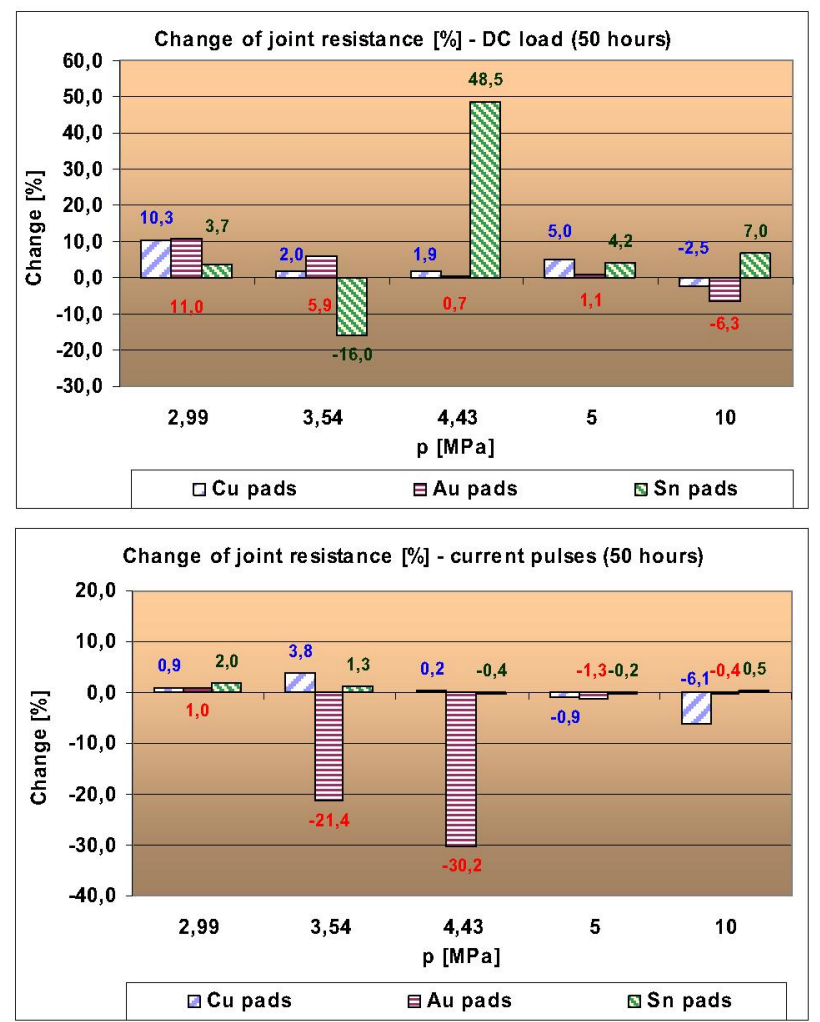

Figure 6. Influence of high current loads and 3 types of pads metallization on joint resistance $R_{s}$ of ACA.

\section{Nonlinearity of the $\mathrm{C}-\mathrm{V}$ characteristics}

There are a few of methods of measurement of nonlinearity. In our case we used the method of measurement of the intermodulation distortion. Intermodulation is the result of two signals of different frequencies being mixed together, forming additional signals at frequencies that are not in general at harmonic frequencies (integer multiples) of either. The largest intermodulation products appear at $\mathrm{fl}+\mathrm{f} 2$ or $\mathrm{f} 1-\mathrm{f} 2$ (second-order intermodulation), and less so at $2 \mathrm{f} 1-\mathrm{f} 2$ or $2 \mathrm{f} 2-\mathrm{f} 1$ (third order intermodulation). In principle, the intermodulation products are described by following equation:

$$
f=n \cdot f_{1}+m \cdot f_{2}
$$

The chosen frequencies:

$$
\begin{aligned}
& \mathrm{f}_{1}=4,106 \mathrm{MHz}, \mathrm{n}=1 \\
& \mathrm{f}_{2}=150 \mathrm{kHz}, \mathrm{m}=2
\end{aligned}
$$

Then measured frequency is $\mathrm{f}=4,406 \mathrm{MHz}$

Nonlinearity measurements have been performed with equipment designed and constructed at the 
department of electrotechnology and carried over 2 joints and SMD resistor. Most frequently expression of nonlinearity of $\mathrm{C}-\mathrm{V}$ characteristics is with third harmonic index THI:

$$
T H I=20 \log \frac{U_{3}}{U_{1}^{n}}
$$

In our case we used power measurement relative to 1 milliwatt - evaluation of nonlinearity in $\mathrm{dBm}$. For evaluation of third harmonics $\mathrm{Uc}=\mathrm{U}_{3}$ in $\mu \mathrm{V}$ we used equation (7);

$$
\begin{aligned}
& U_{c}=224 \cdot 1000 \cdot 10^{N I / 20} \quad[\mu \mathrm{V}] \\
& N I=20 \cdot \log \frac{U_{c}}{U_{1}}[\mathrm{dBm}]
\end{aligned}
$$

where NI is nonlinearity index (measured) [dBm]

$\mathrm{U}_{1}=224 \mathrm{mV}$ - reference voltage $\left(\mathrm{Z}_{0}=50 \Omega\right)$

(if $\mathrm{NI}=-107,08 \mathrm{dBm}$ then $\mathrm{U}_{\mathrm{c}}=1 \mu \mathrm{V}$ )

\section{Tested Isotropic Conductive Adhesives:}

Measurement of nonlinearity is in electrotechnics sometimes used for evaluation of quality and reliability prediction. From other experiments there is clear that this method is very sensitive for small shifts of joint quality. In our case the results are similar - the lowest nonlinearity of adhesive joints has been achieved on common used $\mathrm{Cu}$ pads while the highest nonlinearity is on Sn pads - this metallization is not suitable for adhesive bonding (Figure 7.).

As was already said in [4], the measurement of nonlinearity is more sensitive for low changes of adhesive joints quality than common used evaluation of electrical resistance. This fact is same for ICAs and also for ACAs joints. In Figure 7 is comparison of nonlinearity of adhesive joints on $\mathrm{Cu}$ pads and $\mathrm{Ni} / \mathrm{Au}$ pas. Electrical resistance of these joints is similar but nonlinearity is much more higher $(+30$ $\mathrm{dBm})$ on Ni/Au metallization of pads. So an effect of additional layers (metallization) can be better registered by measurement of nonlinearity rather than with evaluation of electrical resistance. Change of nonlinearity due to high current load is depicted in Table 5. DC load has a little higher effect on nonlinearity but there are no definable trends.
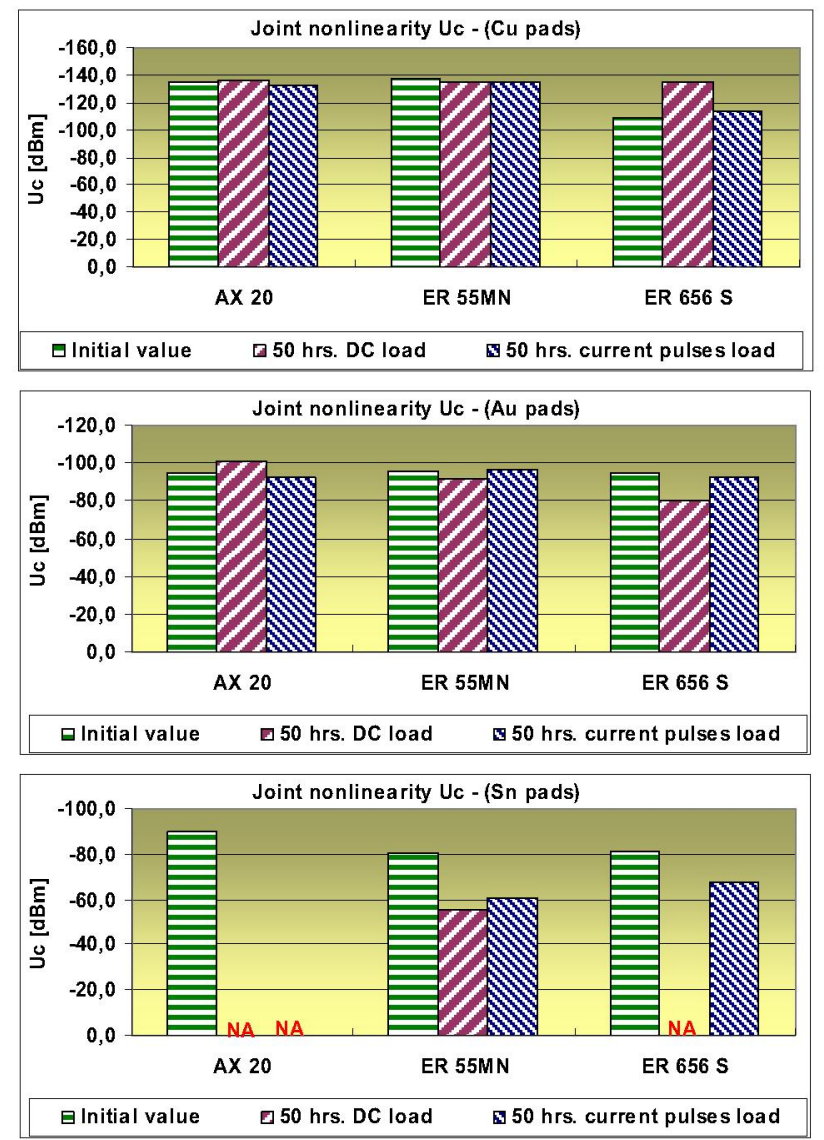

Figure 7. Influence of high current loads and 3 types of pads metallization on nonlinearity of ICAs joints.

\begin{tabular}{|c|c|c|c|}
\hline \multicolumn{4}{|c|}{ Change of joint nonlinearity [\%] - DC load (50 hours) } \\
\hline & Cu pads & Au pads & Sn pads \\
\hline$A \times 20$ & $-14,3$ & $-53,0$ & NA \\
\hline ER 55MN & 28,1 & 64,0 & 1712,1 \\
\hline ER $656 \mathrm{~S}$ & $-94,7$ & 482,5 & NA \\
\hline \multicolumn{4}{|c|}{$\begin{array}{c}\text { Change of joint nonlinearity [\%] - current pulses (50 } \\
\text { hours) }\end{array}$} \\
\hline & Cu pads & Au pads & Sn pads \\
\hline $\mathrm{AX} 20$ & 31,0 & 36,6 & NA \\
\hline ER 55MN & 25,0 & $-9,8$ & 930,7 \\
\hline ER $656 \mathrm{~S}$ & $-41,2$ & 37,9 & 420,9 \\
\hline
\end{tabular}

Table 5. Change of nonlinearity of tested ICAs after 50 hours of high DC and current pulses load.

\section{Tested Anisotropic Conductive Adhesive:}

Nonlinearity of $\mathrm{C}-\mathrm{V}$ characteristics of ACA joints has been also analyzed. Influence of bonding pressure is shown in Figure 8. Differences between $\mathrm{Cu}$ and $\mathrm{Sn}$ metallization are minimal and shapes of curves are also very similar. So mechanism of creation nonlinearity and also values of measured nonlinearity are very analogous for these two types of materials. 


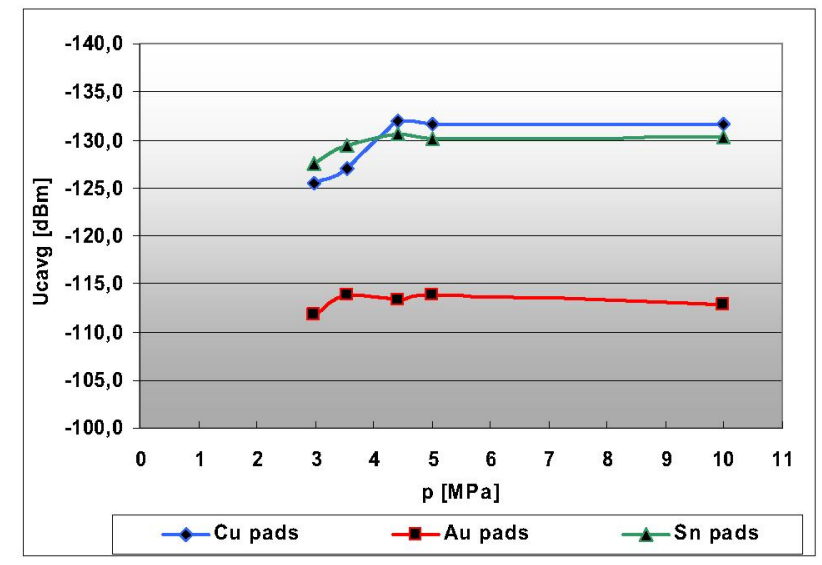

Figure 8. Effect of bonding pressure and pads metallization on nonlinearity of ACA.

On the other hand the nonlinearity of ACA joints on $\mathrm{Cu}+\mathrm{Ni} / \mathrm{Au}$ pads is over $+15 \mathrm{dBm}$ higher for whole range of tested bonding pressure (3-10 Mpa). As was already said, this is probably caused by many boundary-lines between layers on PCB pads. These boundaries provide additional nonlinearity in interconnections between components and substrates and bonding pressure can not eliminate it. Change of ACA joint nonlinearity is shown in Figure 9. Changes of nonlinearity are mainly between $\pm 60 \%$ for all bonding pressures and for all types of pads metallization. Nevertheless there are also some unexpected extremes especially for high DC load of adhesive bonds on Sn pads.

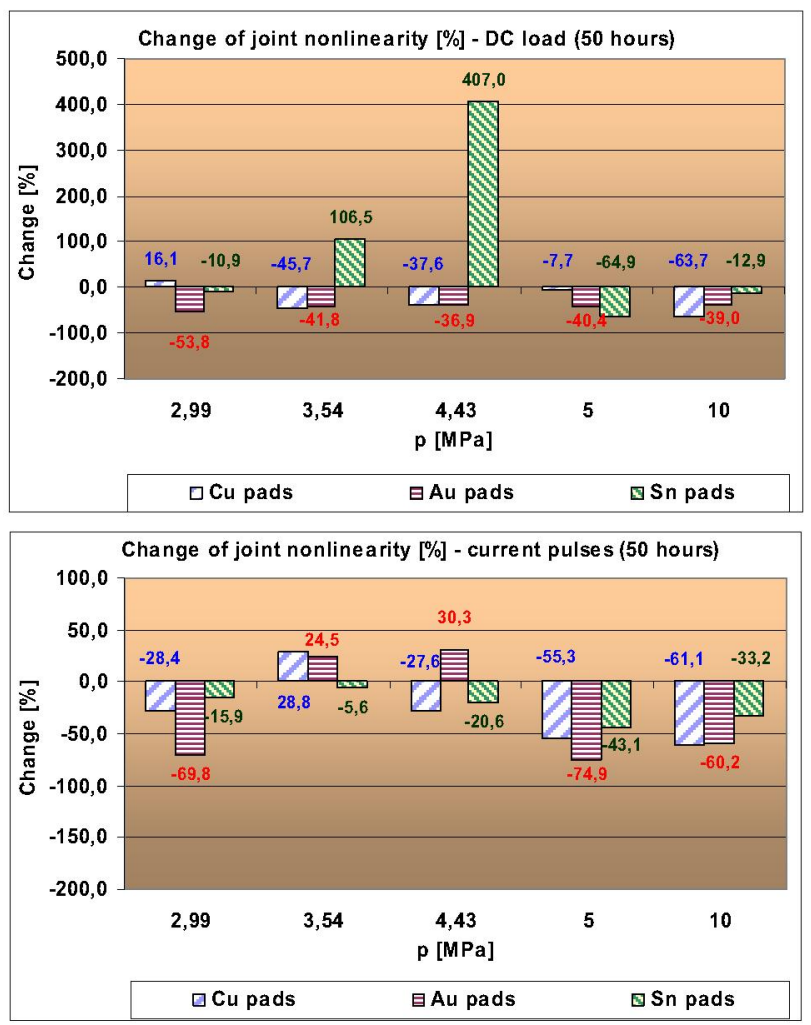

Figure 9. Influence of high current loads and 3 types of pads metallization on joint resistance $R_{s}$ of ACA.

\section{Conclusions}

This experiment has been focused on investigation of high current load of ICAs and ACAs. Two types of load (DC and current pulses) have been applied on three types of pads metallization. Electrical resistance is typical parameter for definition of quality of electrical connection. Measurement of nonlinearity of $\mathrm{C}-\mathrm{V}$ characteristics shows big potential as a diagnostic tool for evaluation of small changes in a quality of adhesive joints. Effect of current load and curing pressure of ACA has been also analyzed with Scanning Electron Microscopy (SEM).Nevertheless no visual defects have been found - Figure 10 .

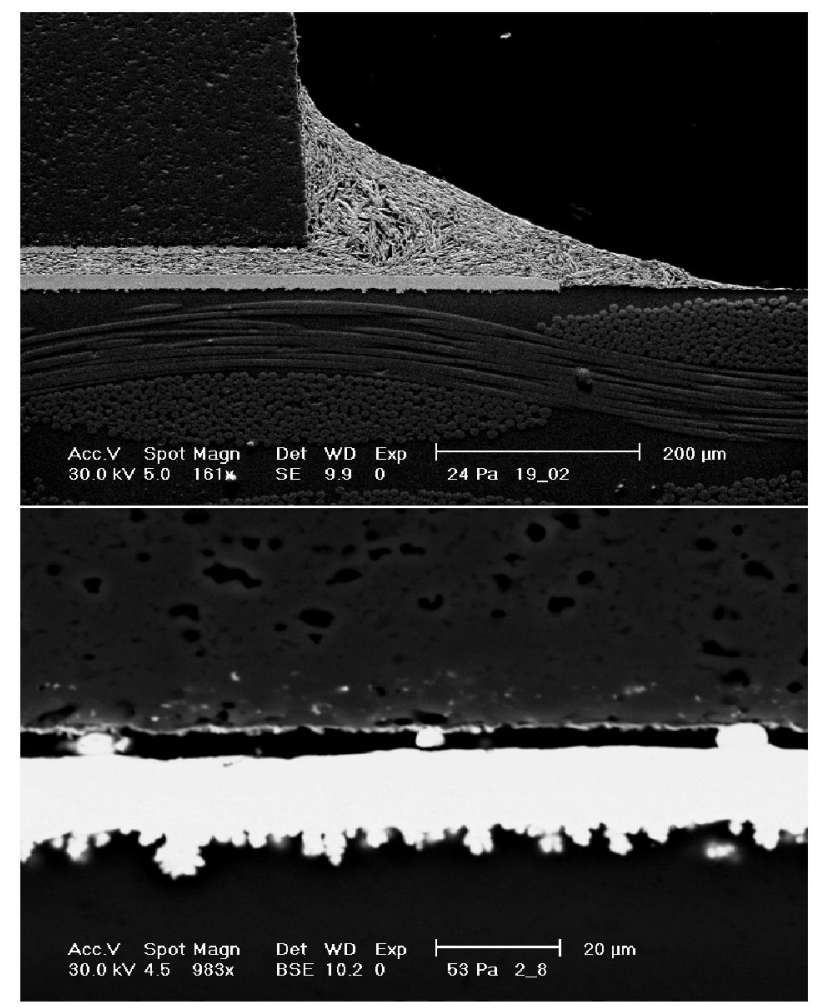

Figure 10. ICA joint (top) after $1 \mathrm{~A} / 50 \mathrm{hrs}$. DC load, ACA joint (bottom) after 1,41 A / 50 hrs. current pulse load

\section{Acknowledgments}

The authors would like to acknowledge for financial support provided by research grant MSM no. 6840770021 - Diagnostic of Materials, Czech Republic.

\section{References}

1. Shyh-Ming Chang, Jwo-Huei Jou, Adam Hsieh, "Characteristic study of anisotropic-conductive film for chip-on-film packaging", Microelectronics Reliability, Vol. 41, Issue 12, December 2001, pp. 2001-2009. 
2. Gautam S., S. Mridha, Tan Tin Chong, "Flip chip interconnect using anisotropic conductive adhesive", Journal of Materials Processing Technology, Vol. 8990, May 1999, pp. 484-490.

3. Duraj,A.,Mach,P.,"Influence of Difference Types of Surfaces on Properties of ECA's and Solders" Proc $15^{\text {th }}$ European Microelectronics and Packaging Conference \& Exhibition, Brugge, Belgium, June. 2005, pp. 604-607.

4. Duraj,A.,Mach,P.,"Experiment of Influence Curing Pressure of Anisotropically Conductive Adhesives on Parameters of Joints" Proc $29^{\text {th }}$ International Conference of International Microelectronics and Packaging Society - Poland Chapter, KoszalinDarlówko, Poland, September. 2005, pp. 91-94. 